This is a pre-print draft version of a published book chapter.

To cite this article, see: Macnaughtan, Helen (2012) 'Building up Steam as Consumers: Women, Rice Cookers and the Consumption of Everyday Household Goods in Japan.' in: Francks, Penelope and Hunter, Janet, (eds.), The Historical Consumer: Consumption and Everyday Life in Japan, 1850-2000. Palgrave Macmillan.

\title{
Building up Steam as Consumers \\ Women, Rice Cookers and the Consumption of Everyday Household Goods in Japan
}

\section{Helen Macnaughtan}

\section{Introduction}

Consumption in Japan, as elsewhere, is strongly gendered. While patterns of consumption have evolved a great deal since the mid-nineteenth century, the importance of gender and the role of women in consumption has persisted, particularly in the context of the rise of the housewife and breadwinner-homemaker model. Scholars have analysed women's association with consumption, and why globally women have become the main shoppers and consumers (de Grazia 1996; de Vries 2008). Research on gender and consumption in countries such as the United States and in Europe has highlighted the relationship between production and consumption. With the separation of home and work over the course of industrial development came a gendered division of labour, within which men's roles and responsibilities became defined by the public domain and by productive work, while women's roles and responsibilities became defined by the private domain and by 'non-work' activities, mainly comprising housework, childrearing, maintaining family life, leisure and consumption (Costa 1994). Francks (2009: 140-1) notes that in Japan '...growth in consumption in the forms that it took could not be divorced from the shifting patterns of work and family organisztion and, in particular, from changes in the role of women within the household and the labor force.' This development has earlier origins, but occurred in Japan most markedly from the 1950s.

In post-war Japan, the ideal womanly role of full-time housewife (shufu) has often contrasted sharply with increasing rates of female participation in the labour market, as Japanese women, particularly the older, married cohorts, have entered the paid economy in growing numbers (Macnaughtan 2006). Japan has also been at the forefront of development in electrical household appliances, involving a distinct growth in time-saving (and time-using) appliances, in these post-war decades. The growing production of this sector of manufacturing has had a major effect on domestic consumption by Japanese households since the 1950s.

This chapter discusses the increasingly important role played by women as everyday consumers in post-war Japan, focusing on their consumption of household and kitchen appliances, specifically the electric rice cooker. Two key areas are explored. First, I investigate the development, production and consumption of this appliance. The electric rice cooker was developed by Japanese manufacturers from the mid-1950s, and was at the time unique to the Japanese manufacturing sector and the Japanese consumer market. It rapidly achieved significance in both domestic and 
export markets. ${ }^{1}$ The analysis will focus on the rice cooker's development and impact in the Japanese market during the post-war years as a key example of the importance of everyday household appliances in the history of gender and consumption in Japan, impacting on women's roles inside and outside the home. The chapter will show that although the rice cooker was in many ways a humble product, it had a revolutionary impact on Japanese women's primary role as housewives.

Second, the chapter places the case-study of the rice cooker within a broader context, discussing the role played by Japanese women as key consumers of appliances and as a gendered consumer group. It will explore the significance of housewives as a consumer group in Japan during the post-war decades, the associated gendering of consumer practices, and the extent to which housewives, as the holders of the purse-strings within the Japanese nuclear household, were empowered by the establishment of the breadwinner-homemaker model.

\section{The importance of rice}

The development of the electric rice cooker was in many ways the product of the history and significance of rice in the Japanese diet and cuisine. Rice was still viewed as the staple food in the immediate aftermath of World War II, when it was often unobtainable. While Japan's rice crop was (at least in theory) controlled by the Food Agency and marketed at controlled prices by state-authorised dealers, Japanese consumers commonly used black market channels to buy rice and other basic commodities. It fell primarily upon women to undertake the everyday struggle to feed and clothe families in this challenging environment, perhaps helping to validate women's postwar role as household managers and controllers of consumption (Francks 2009: 148, 152).

Over time, particularly from the mid-1960s, there was some diversification in the Japanese diet involving the inclusion of Western-style ingredients - notably the consumption of bread for breakfast (helped by the convenience of new electric toasters) and sandwiches for lunch. However, the format of 'rice plus side dishes' persisted as the basic pattern for most proper meals in the Japanese household. Rice remained central to the Japanese diet and the image of the Japanese housewife. The Japanese Housewives Association (Shufuren), established in 1948 and probably the most important consumer group in post-war Japan, adopted the rice paddle (shamoji) as their symbol.

Rice had long been cooked in Japan using kamado, earthenware (later also metal) cooking pots placed directly over open fires. Cooking rice in a kamado involved much skill and some mystique, and characterised a woman as a good wife. The first experiments with the use of electricity to cook rice, described as 'simple tubs with heating coils attached', took place in the mid-1920s (Toshiba 2009). In the late 1940s, Mitsubishi Electric, Matsushita and Sony all produced this kind of electric rice cooker, but, like earthenware and metal kamado, they were labour-intensive, requiring total attention while cooking. The use of traditional kamado thus remained prevalent across Japan.

\footnotetext{
${ }^{1}$ For a discussion of the impact of the electric rice cooker in Asian markets, see Nakano 2009
} 
It was in the key year of 1955, when the Liberal Democratic Party (LDP), which subsequently went on to govern Japan unchallenged until the 1990s, was established and pre-war levels of national income were regained, that the first automatic electric rice cooker was launched. The nature of this innovative rice cooker of 1955 was conditioned both by the importance of rice, and the association of women with the cooking of rice. It is this that gives it a key position among the electrical appliances being produced and consumed in Japan at this time.

\section{The development of the Japanese electric rice cooker - the Toshiba story}

The rice cooker was developed specifically for the market in Japan, where meals were focused around rice and the housewife needed to cook rice daily. The appliance remains an essential and ubiquitous item in Japanese households. Many studies have charted the rise of Japanese electrical and household appliance production, but few studies have focused on production and demand for the rice cooker, or the role Japanese housewives played in its development as a key household appliance. Nakano (2009) describes the development of the Japanese rice cooker abroad, analysing its adaptation and advance via Hong Kong into the rest of the Asian market, but the importance of the electric rice cooker for the Japanese domestic market remains largely unexplored, despite its importance for everyday lives, particularly those of women. Nakano (2009:1) suggests that the launch and success of the electric rice cooker in the 1950s was immediately 'overshadowed by that of the "Three Sacred Treasures" - the television, washing machine and refrigerator - that were considered the true icons of modern Japanese living. In comparison, the rice cooker was seen as a minor, though useful, appliance targeted at housewives (okusan-yōhin).' This highlights the crucial fact that the cooking of rice had long been considered routine women's work, though the end product was consumed by all members of the family. The three 'Sacred Treasure' appliances, particularly the television, seemed much more exciting in terms of physical arrival, impact, size and presence in the Japanese house. This chapter will argue that the more subtle presence of the rice cooker in the Japanese home should not lead us to overlook its impact, or its success as a product.

The Toshiba company was the first to develop an automated electric rice cooker. The company records that it took on the challenge of developing the electric rice cooker around 1950, 'certain that Japan would fully enter the era of the electric home appliances in the near future' (Toshiba, Firsts of their Kind: 33-4). Yamada Shogo, then the Development Department Manager in Toshiba's Home Appliances Division, took the lead. This story was captured in one episode of the NHK Project $X$ : Challengers series, ${ }^{2}$ which has been used here as a source, together with Toshiba records. In the Project $X$ documentary, the development of the rice cooker is told as a story of Yamada, the 'silver-tongued' Toshiba salesman, and his collaboration with

\footnotetext{
${ }^{2}$ Project X: Challengers was a weekly documentary series produced by NHK. A total of 177 episodes were aired between March 2000 and December 2005 documenting post-war technological innovations in Japan, and telling the 'forgotten stories of organisations and people' behind these innovations. The origins of these innovations were meticulously researched by NHK, which makes the programme an interesting historical source. It was also a highly popular series in terms of audience ratings in Japan. The programme on the origins of the first automated electric rice cooker was programme No.42 of the series.
} 
Minami Yoshitada, manager of a small, family-run factory in the Ōta ward of Tokyo which was on the brink of bankruptcy. Together Yamada, Minami, and Minami's wife and six children, turned the family home into an 'engineering laboratory' to develop the first electric rice cooker for Toshiba and for the Japanese market. This development is described repeatedly in the programme and in Toshiba documentation as a 'revolution for the Japanese kitchen' (NHK 2002; Toshiba Corporation, Firsts of their Kind: 33-4).

The Project $X$ story begins in 1951, with Allied Occupation troops and their families beginning to pull out of Japan. The programme records that Americans living in Japan were 'rich', and had been ordering many appliances, such as washing machines and refrigerators, so their withdrawal was a big blow to small neighbourhood factories acting as subcontractors to the larger Japanese manufacturers. Minami's small factory had supplied electric water heaters to the occupying forces, but orders had dried up. The production line had been halted, creditors were calling on the family and they faced imminent bankruptcy.

Yamada is introduced into the Project $X$ story as a 'famous salesman', who entertained audiences around Shinbashi Station with his self-made kamishibai (paper card theatre). Toshiba had already launched the electric washing machine, which Yamada demonstrated and sold, telling housewives that each year they were washing by hand the weight of an elephant. Yamada also spoke to housewives all over Japan, and was told that cooking rice was actually their hardest chore. They began the day at 5:00 sitting in front of a kamado, and were regarded as a 'failed housewife' if they could not control the fire properly. Yamada was also told that having to cook rice three times a day meant insufficient sleep. Yamada's idea of developing an automated electric rice cooker did not initially find favour with his superiors at Toshiba. Alternatives to the kamado already existed in the form of the electric coil rice cookers and rice cookers for use on gas hobs, and both Mitsubishi and Matsushita had already failed in their attempts to develop an automatic electric rice cooker. It is also recorded in the Project $X$ documentary that Yamada's superiors somewhat 'chauvinistically' believed that a woman who wanted to sleep rather than cook rice was a failure as a wife. Yamada therefore failed to secure a development budget. When Minami subsequently came to Toshiba begging for subcontracting work, and Yamada heard that Minami's factory produced electric water heaters and had extensive knowledge of heating systems, he suggested to Minami that he try and develop an automatic electric rice cooker. Having no knowledge of rice cookers, Minami reportedly hesitated at first, but on reflection thought it might help him get out of his difficulties, and when he got home he asked his wife Fumiko to help him. He borrowed money for the project using his house as security, and started to work on the development in 1953.

At this point the story really becomes Fumiko's, as it describes her lengthy struggle to research the heat levels and temperature changes involved in the successful cooking of rice. The programme reports how she sat for hours in front of her openfire kamado and experimented with existing (non-automated) electric rice cookers, attempting with her husband to solve the biggest challenges of all - when and how to adjust the temperature of the cooker so that the rice would not burn, and how to create a cooker that would not only cook rice successfully, but also switch off automatically 
after 20 minutes of boiling. ${ }^{3}$ Yamada and a technician from Toshiba then assisted with the project, supplying Minami with a 'bi-metallic' strip which would bend at high temperature, cutting off the switch automatically. Yamada's suggestion that the rice cooker had to work in any climate, including the cold winter of Hokkaido and the hot summer of Kyūshū, required Fumiko to test the cooker for endurance over a period of many months, experimenting outside on chilly winter mornings, on the roof of the family house in the scorching sun, next to a steaming bathroom and inside a kotatsu. ${ }^{4}$ Minami tried making many prototypes of cooker using aluminium and glass, but the heat always escaped from the cooker in cold conditions. As Fumiko became ill testing the prototypes in cold winter weather, in 1955 the rest of the family pitched in to help. Chikashi, the third son, commented in the programme: 'my mother used to say, if we succeed with this development, Japanese women will not need to cook rice three times a day. They could do something else for three hours a day. With an automatic rice cooker, they could go to work as men do' (NHK 2002).

By 1955 Minami was despondent, and financially on the brink of losing his house and factory. Yamada commented how he had seen cooking pots in Hokkaidō during winter covered with tin and asbestos to keep the heat in, and Minami and one of his sons thought it might be possible to cover the cooker with a triple-layered iron exterior. This final prototype was tested in an ice warehouse at minus 10 degrees, and proved successful. The Project $X$ documentary notes this moment as the 'birth of the world's first automatic electric rice cooker' (NHK 2002).

Determined to sell the product after the huge personal sacrifices of the Minami family, Yamada attempted to sell the convenience of this first automated rice cooker to housewives in northeast Japan, but the response was slow. The product was priced at $¥ 3,200$, at a time when the average basic monthly salary was around $¥ 10,000$. Housewives said it was too expensive, and that they could cook rice in the old way, even though it was time-consuming. However, when Yamada showed them that the cooker could also produce takikomi gohan (rice mixed with soya sauce), which was very difficult to cook in a traditional kamado as the soy sauce was prone to burning, the housewives were reportedly very surprised and applauded this demonstration. Yamada's report on this demonstration led to the manufacture of 700 completed units, and on 10 December 1955 Toshiba began to sell this first electric rice cooker nationwide (Toshiba Corporation, Firsts of their Kind). Within two years Minami's small factory was operating three shifts day and night, and had produced more than 10,000 rice cookers.

\section{Selling the electric rice cooker on the Japanese market}

The new electric rice cooker rapidly revolutionised the process of rice cooking in Japan. Matsushita (now Panasonic) launched its own model the year after Toshiba, and a shaky start was followed by huge commercial success. Within the first year, Toshiba was producing some 200,000 rice cookers a month, and by 1960 automatic rice cookers could be found in half of all Japanese households. The company's 'award-winning design remained unchanged for nine years', and by 1970 Toshiba had an annual output of 12.35 million rice cookers (Toshiba 2009). Over the high-growth

\footnotetext{
${ }^{3}$ The programme records how the many trial-and-error experiments needed a ton of rice, which the Yamadas managed to acquire through a contact who used the black market.

${ }^{4}$ Kotatsu is a low table covered with a quilt, with heating built underneath, so that the lower body under the quilt is kept warm.
} 
decades, the three big electrical appliance producers - Toshiba, Matsushita and Hitachi - together with other niche players such as Zōjirushi and Tiger corporations, developed further the technology of their electric rice cookers for consumption on the Japanese domestic market. Matsushita (Panasonic) commented that the 'electric automatic rice cooker streamlined housework, causing a sudden increase in demand for automatic rice cookers, unlike that for any other home appliance, which led to what was called the rice cooker boom of 1957' (Panasonic Corporation 2011). The electric rice cooker was therefore a product that had a sudden and significant impact on the consumer market in Japan.

Historical data on the production and diffusion of electric rice cookers after 1955 are somewhat difficult to establish, and data on electric rice cooker production is omitted from official manufacturing statistics before $1985 .^{5}$ This is not the case for other household and kitchen appliances; TVs, washing machines, refrigerators, vacuum cleaners, sewing machines and even kotatsu are all included in METI statistics from the 1950s. ${ }^{6}$ Figure 1 shows that the production of gas rice cookers declined between 1965 and 1983 in the face of competition from its electric counterpart. For the period 1985-2004, for which data exist, we find that the volume of production of electric rice cookers displays a trend of declining annual production similar to that of other key appliances, ${ }^{7}$ but the relatively high volume of production compared to many other key appliances suggests an ongoing and stable consumer market for this product. Figure 2 shows that the value of electric rice cooker production was, not surprisingly, much lower than that of the larger, more expensive appliances, but comparable to appliances of similar size and durability, such as microwave ovens and vacuum cleaners.

\footnotetext{
${ }^{5}$ These statistics were compiled by MITI, the Ministry of International Trade and Industry (now METI).

${ }^{6}$ A contact at Toshiba Corporation was surprised when I mentioned this omission in the METI statistics. When I informally asked why he thought these data were not recorded, he commented that maybe it was because it was a 'women's product'. I was unable to pursue the omission of this data with METI.

${ }^{7}$ This applies only to domestic production; overseas production of electric appliances has grown with the 'hollowing out' of Japanese manufacturing in recent years.
} 
Figure 1: Production of Selected Home Appliances, 1960-2004 (1,000 units)

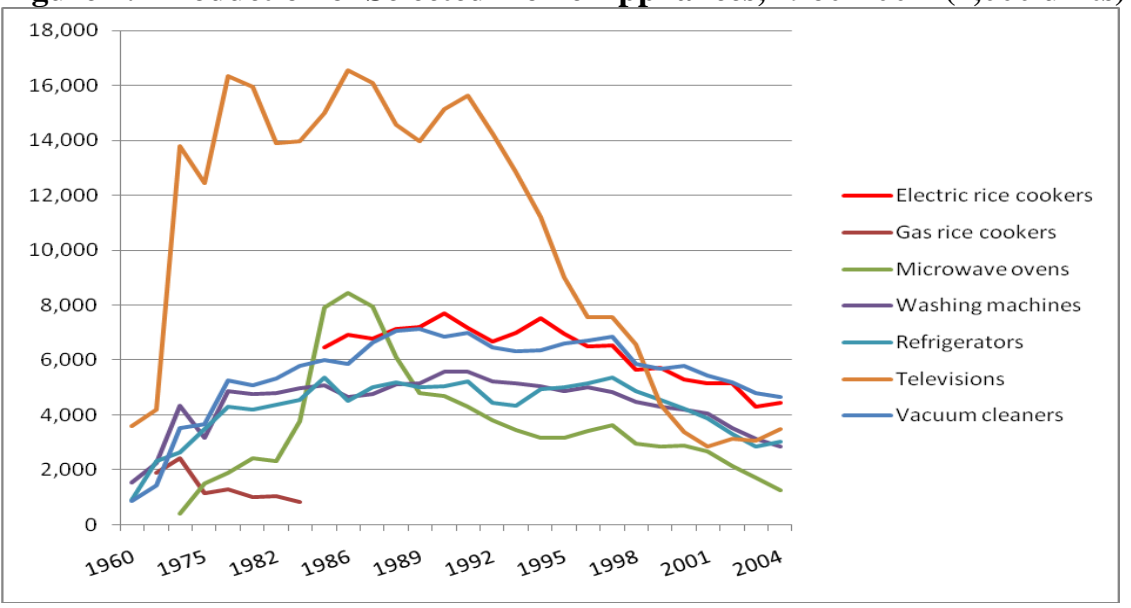

Source: Statistics and Research Bureau, Ministry of Economy, Trade and Industry (METI)

Figure 2: Value of Selected Home Appliances production, 1960-2004 (¥ billion)

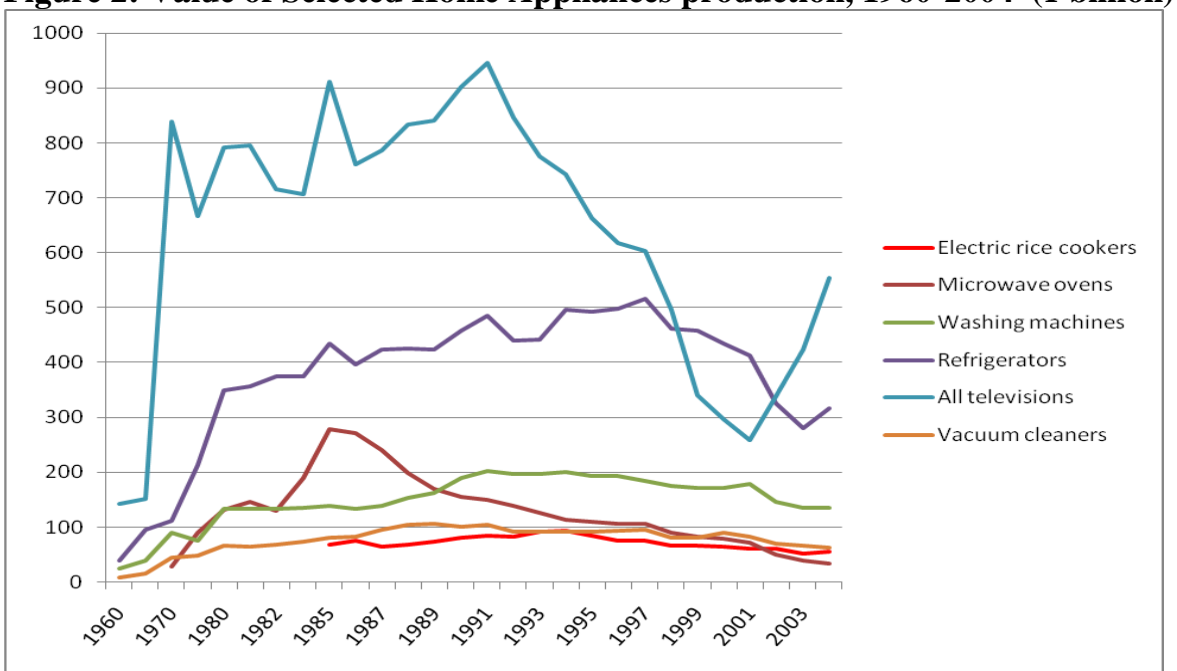

Source: Statistics and Research Bureau, Ministry of Economy, Trade and Industry (METI)

That production volume was much higher in the early years (late 1950s onwards), when the electric rice cooker was a newly available and innovative product on the market, is confirmed by comparing the available METI data (1985-2004) with data from Toshiba (Figure 3). Toshiba's 1970 output of 12.35 million electric rice cookers is comparable to METI's figure for TV production the same year (13.78 million). It therefore seems likely that the inclusion of electric rice cooker production from other companies would make it one of the most significant appliances on the domestic market at the time, and potentially the largest in terms of annual domestic production. 
Figure 3: Production of Electric Rice Cookers, 1970 \& 1985-2004 (1,000 units)

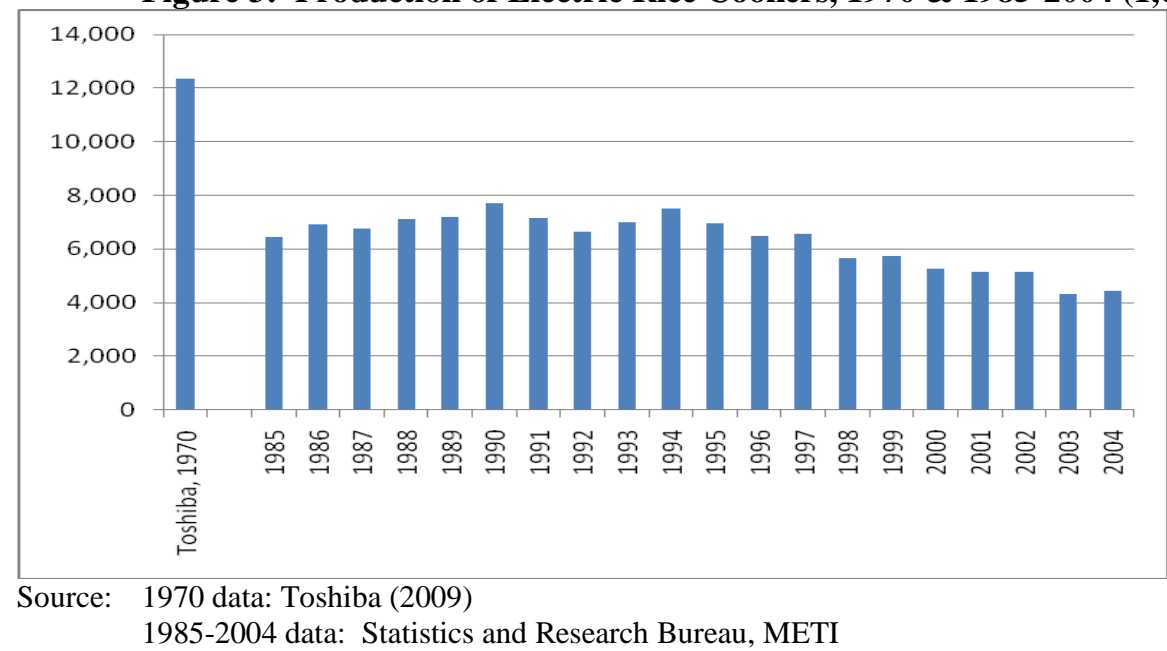

Over time the electric rice cooker has seen continual technological development, as newer and better models have been launched on to the domestic market. In the early 1960s, some manufacturers introduced a function that could keep rice warm after cooking until it was served, as well as some models with a timer switch, for setting cooking times in advance. Figure 4 shows successive new rice cooker models that Toshiba has developed since pioneering its original model in 1955.

Figure 4: Development of the Electric Rice Cooker by Toshiba, 1955-2005
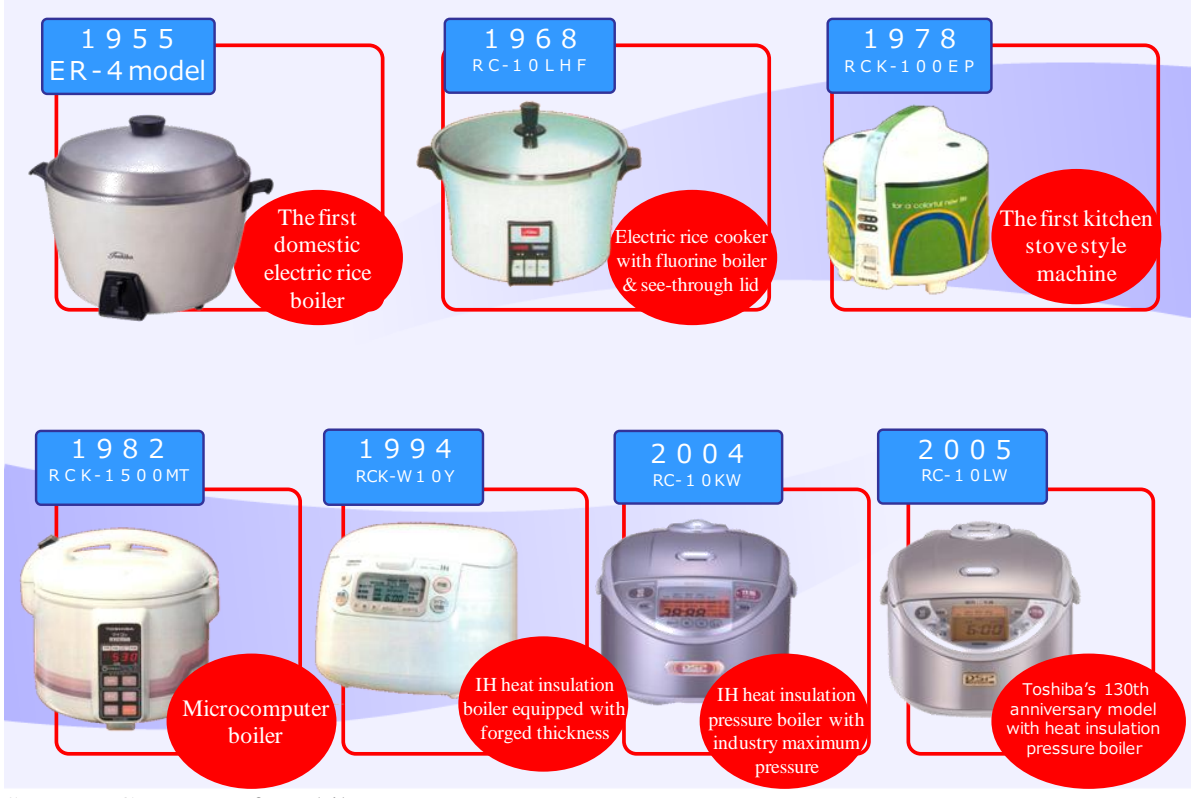

Source: Courtesy of Toshiba

Note: Description captions translated by myself from original Japanese captions supplied by Toshiba

The initial two models prior to 1978 were simple 'rice boiling' models that allowed for rice to be cooked at the touch of a button and, from 1968, allowed the 
cook to view the progress of the rice through a glass lid. The 1978 model was described as more 'oven-' or 'kitchen stove-'like in style, had a colourful 1970s vibe, and allowed for easy transportation by means of a handle at the top. From 1982, the rice cooker became electronic, with microcomputer technology enabling a range of automation settings and options. Later models focussed on induction heating (IH), heating insulation, and pressure steaming technologies. Over time, therefore, Japanese consumers could buy newer, more efficient models reflecting their desire to keep up with the latest gadgetry and produce on an everyday basis even more efficiently cooked and better tasting rice.

\section{The consumption of electrical household appliances in Japan}

The production of consumer durables, including household and kitchen appliances, in post-war Japan, was, of course, a significant sector of the Japanese economy (Partner 1999). Growth in the domestic demand for electrical household appliances went hand-in-hand with growth in the production of these goods by Japanese manufacturers. The large and growing market allowed Japanese manufacturers to test their new technologies and products and enhance their designs before moving into export markets. How domestic producers tested, marketed and sold their products to Japanese consumers and households is therefore an important area of investigation. From the perspective of consumption, we need to ask why Japanese households were buying these appliances, who was making the decision to buy, and what impact home appliances, particularly kitchen appliances, had on the lives of Japanese women in terms of their primary role as 'home-makers'.

The growth in the number of household appliances was also significant for the Japanese kitchen. The kitchen (daidokoro) has always been a focal point of the Japanese household (Kosuge 1991; Sand 2003), and Sand (2003) has suggested that the kitchen evolved to become the 'housewife's laboratory', where Japanese women were expected not just to cook but to practice the new field of home economics, focusing on such issues as nutrition, hygiene and budgets. The preservation and processing of food at home had long been an important practice, and the kitchen was the 'factory' for these processes. From around 1890 the introduction of Western-style cooking and kitchen equipment (designed to be used while standing) meant that gradually the floor in the Japanese home ceased to be used for food preparation or serving meals (Yamaguchi 1988; Yamaguchi 2008), but Partner suggests that kitchens in much of rural Japan were until the late 1950s were 'miserable places' where women still squatted on earth floors to do most of the food preparation, and campaigns to improve rural kitchens were part of a broader 'lifestyle improvement' process (Partner 2001: 492-3). Kitchens became more linear and 'set' in terms of layout and style, encouraging a process more akin to an assembly line.

From around 1956, the kitchens of housing complexes built by the Japan Housing Corporation had set kitchens in sparkling stainless steel, including a gas cooker, kitchen counter and sink arranged in a linear design. By the 1960s it had become customary to display cooking utensils, lining them up on shelves or hanging them along the wall above the counter, but during the 1960s Japanese household magazines began to criticize this practice as a sign of a disorderly kitchen and poor domestic management, and set-kitchens began to include drawers and cupboards (Yamaguchi 2008). Into the new and evolving space of the compact dining-kitchen 
(DK) came a growing range of Japanese- and Western-style kitchen equipment and appliances. The electric toaster appeared in 1953, followed by the electric rice cooker in 1955, the electric refrigerator, the microwave oven and, by the early 1970s, induction-heating devices, particularly in rice cookers (Yamaguchi 2008). Appliances ranged from the large-scale - refrigerator and washing machine - to smaller-scale and uniquely Japanese appliances such as the electric kotatsu, electric rice cooker and electric vacuum jugs (potto) for storing and dispensing hot water for green tea preparation. With consumption boosted by the modish slogan of mai homu ("my home'), these appliances changed both the concept and environment of cooking within the Japanese household and the time spent by women on the preparation and production of food.

Research on the development and diffusion of electric household appliances has identified them as falling into two distinct classifications: 'time-saving' goods, such as electric washing machines and electric vacuum cleaners, and 'time-using' goods, which required the use of discretionary time, such as radios and TVs (Bowden and Offer 1994). In many countries the diffusion of time-using goods as items of consumption appears to have been much faster than that of time-saving goods, and this was also true in Japan, where the TV was the key 'Sacred Treasure' item in terms of production and diffusion. However, it was suggested above that the electric rice cooker may have surpassed the TV in production and diffusion during the 1960s and 1970s. It may have been a 'humble appliance targeted at housewives (okusan-yōhin)' (Nakano 2009:1), but its impact in the market was enormous.

\section{Women as the target market for electric rice cookers}

The emergence of the urban, middle-class, nuclear Japanese family from the 1950s and 1960s was associated with an ideal 'model' of men commuting to long hours of work, and women, even those who had paid employment, being primarily responsible for the everyday management of the household. That responsibility included making decisions regarding allocation of expenditure within the family budget, especially relating to day-to-day shopping and cooking for the family. Japanese women, or rather Japanese 'housewives', were thus viewed as the key target consumers for the new electric rice cookers from the mid-late 1950s. As housewives, they were the most likely to decide to purchase the product, and were (correctly) assumed to be the ones who would use it in the home. The image of the modern Japanese housewife was widely used by companies marketing the electric rice cooker and other household appliances.

The advertisement in Illustration 1, with its modern-style Japanese woman opening the cooker lid, records the launch in 1955 of Toshiba's first electric rice cooker (the ER-4 model). 


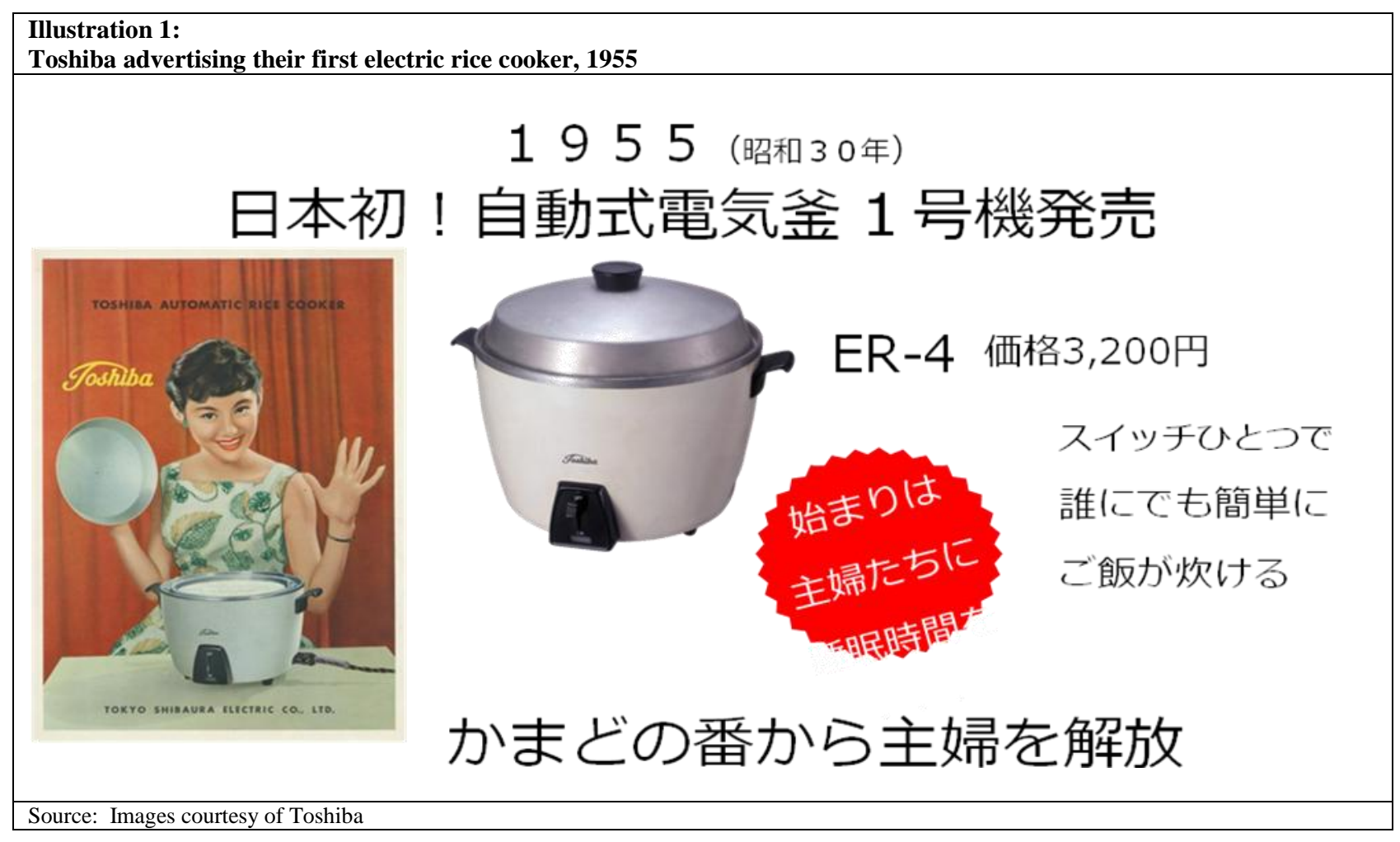

It includes several interesting slogans:

'Releasing housewives from the vigil of the stove' (kamado no ban kara shufu o kaihō suru)

'Giving housewives time for sleep' (hajimari wa shufutachi ni suimin jikan o ...)

'With one switch anyone can easily cook rice' (suitchi hitotsu de dare ni demo kantan ni gohan ga takeru)

The slogans reveal something of the meaning of the electric rice cooker within Japanese households. Housewives would be liberated from the task of standing or squatting at the kamado, constantly keeping an eye on the rice, so women's burdens would be reduced. Japanese women could now sleep more in the morning, instead of getting up to prepare rice for breakfast, or during the day, with perhaps a cat-nap while the rice for the evening meal was bubbling. The electric rice cooker was therefore clearly a 'time-saving' device for women, in terms of everyday routine and hours spent on rice cooking. However, Toshiba's marketing slogans also imply that although the appliance may have made it easier for the housewife to carry out her rice-cooking duties, it did not free her up for anything significantly more productive than some rest or down time. The third slogan subtly suggests that anyone, and not just women or housewives, could now easily perform the task of cooking rice, though who those others may be is not indicated. It seems unlikely that the intention was to suggest that rice cooking could now be a man's daily task too; rather, that any housewife could now produce perfectly steamed rice, no longer needing to acquire the skill from her mother-in-law (and being unfavourably compared to her).

In 1956 Toshiba enlisted the electric power companies to help distribute the new electric rice cooker and win the trust of consumers suspicious of the failure of earlier electric rice cooker models in the late 1940s (Toshiba 2009). In those early 
days, Toshiba and Matsushita took their product directly to the consumer, with employees going from home to home to demonstrate this first automated model, and holding appliance and cooking demonstrations in public spaces and in new apartment complexes (e.g. Senri New Town in Osaka in the case of Matsushita) (Nakano 2009). Toshiba also held demonstration sales within department stores, and later in its own electrical appliance retail stores. One Toshiba manager recounted that Toshibafranchised small electrical stores were the key sites for retail sales in the Japanese domestic market until the 1990s, when they were replaced by larger-scale electrical stores not affiliated to any one company. Illustration 2 shows the latest Toshiba model on sale in a Japanese department store. In the first photograph a group of male customers is gathered around the new rice cooker, while the sales assistant is a woman.

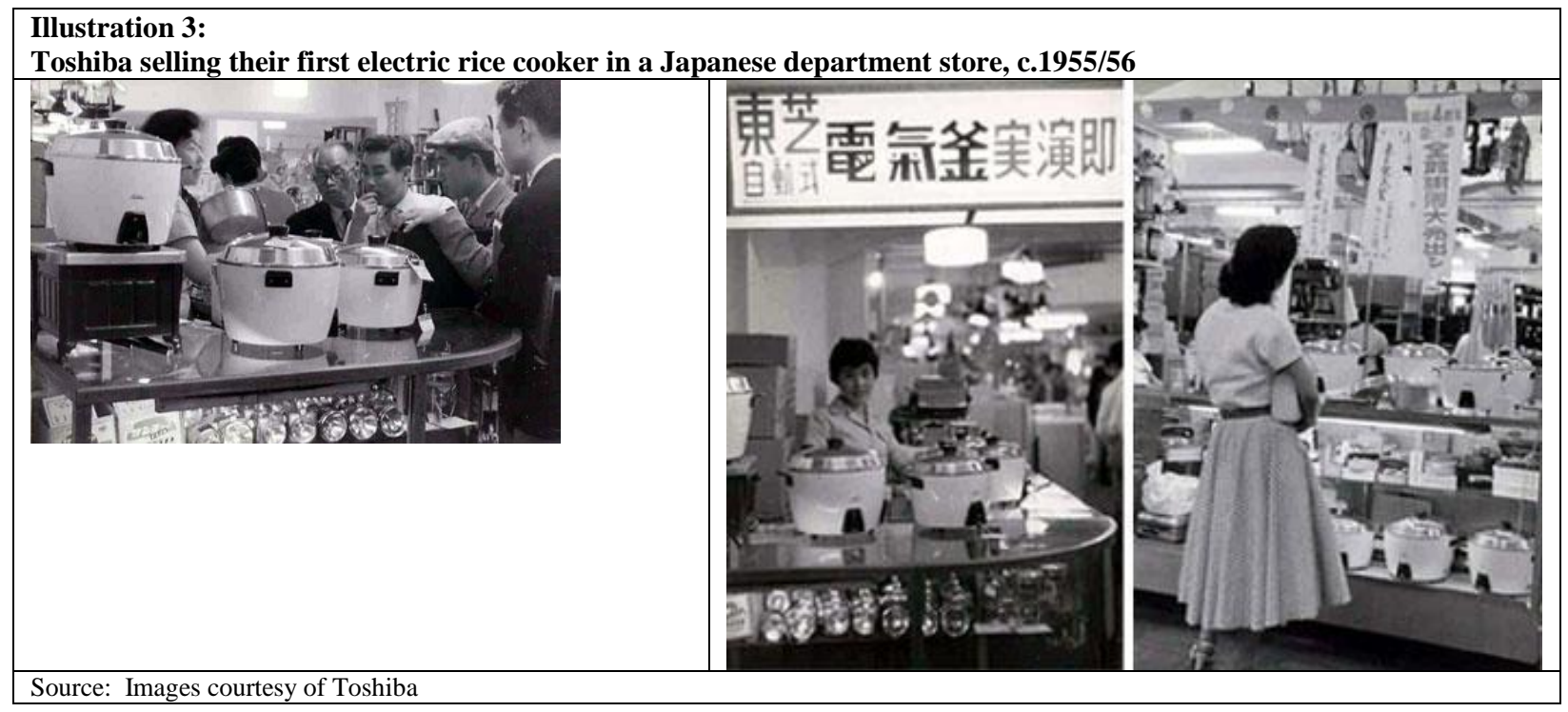

Women also helped to popularise and sell these appliances directly. By the early 1960s, Matsushita employed female retailers in their 'Mom and Pop stores' to sell household appliances including the rice cooker. These female retailers were centrally trained and kept up-to-date with new products (Nakano 2009). Women were eventually also involved in the design and engineering of rice cookers. Nakano (2009) describes how, until the 1970s, Matsushita used all-male teams of engineers to research and design the appliances, an assignment regarded as 'disappointing' by male engineers who would have preferred to work in the higher-tech divisions within the company. However, in 1979, Matsushita hired a 'female rice specialist' with a Masters Degree in Home Economics, who went on to make subtle yet successful advances in the technology required to regulate the temperature inside the cooker so as to enhance cooking and flavour and produce 'perfectly steamed rice'. Matsushita then began to hire female engineers in their rice cooker division, who became informally known as the 'rice ladies' within the company (Nakano 2009:132-6), as well as women in their marketing teams. One of the early R\&D 'rice ladies' went on to become director of Matsushita's Cooking Appliances Business Unit, and has described how the Japanese 'obsession with perfectly steamed rice' has meant that the market for rice cookers in Japan has developed very differently from that in other parts of Asia, because Japanese consumers view the rice cooker as only to be used for 'steaming white rice and refuse to cook anything else in the pot', whereas in other 
parts of Asia the rice cooker has to be a 'versatile multi-cooker' in order to sell to consumers (Nakano 2009: 155).

By implication, this means that Japanese consumers have been more willing to spend money on an appliance the function of which is only to 'perfectly steam rice'. It would seem, therefore, that for Japanese housewives, still reluctant to do anything that might damage the taste of future batches of steamed rice, the production of 'perfect rice' requires a dedicated appliance, and the cultural implications of this have significantly influenced how the rice cooker has been designed, marketed and consumed in the Japanese domestic market. However, this has also meant that the electric rice cooker in the domestic market has remained a somewhat humble, minor and housewife-oriented appliance compared to its more 'elevated' status elsewhere in Asia (Nakano 2009: 176).

Given the focal role of rice cooking in women's housework duties and the skill required to make good rice, the arrival of the electric rice cooker in the mid1950s revolutionised food preparation, cooking routines and meal preparation hours for Japanese women, and its impact on the market was immediate and significant. Sazae-san, the central housewife character in a highly successful comic-strip and, as one Japanese academic has commented, a lens through which to view the life of ordinary Japanese during the early post-war decades (Tamaki 2003), started using a Toshiba electric rice cooker in 1960 (Goo 2005), suggesting that just four years after its product launch the automatic electric rice cooker was on its way to becoming an essential everyday item in Japanese households..

It is debatable how far appliances like the electric rice cooker were really time-saving in freeing up Japanese women to spend time on other activities, such as paid employment or leisure activities, and how far these appliances simply enabled women to divert their attention to other household tasks, further to creating or enhancing the image of the 'modern' Japanese housewife and the 'modern' Japanese home. Women who were full-time housewives may simply have devoted more time to other housework and the preparation of more elaborate side-dishes to accompany their perfectly steamed rice. However, it is certainly possible to argue that key appliances, including the electric rice cooker, at the very least helped to free housewives from formerly time-consuming daily routines, and enabled them to enter paid part-time employment. The new 'bundle' of time-saving household appliances increasingly owned by the average family meant that women could perform daily housework and food preparation in less time than previously. With rising demand for female labour, especially part-time ( $p \bar{a} t o$ ), from Japanese companies seeking to maintain a workforce under the conditions of rapid economic growth (Macnaughtan 2005), these key home appliances added to the 'supply side' conditions enabling married women to enter paid employment while still fulfilling their key 'housewife' role.

As her son Chikashi mentions in the Project $X$ documentary, Fumiko had considered the possibility of freeing women from rice-cooking duties to go out to work like men, while experimenting with the development of Toshiba's first automatic rice cooker. Chikashi also comments in the programme that 'leading manufacturers had failed to develop a successful electric rice cooker since the end of the Taishō era. I think the reason why ours was successful was because women and 
families participated in the development' (NHK 2002). In Japan (and in Western markets), manufacturers and advertisers gradually came to realise from the 1960s that products like the electric rice cooker, targeted at or destined for consumption by women, benefited from having women involved in both development and marketing.

\section{The role of Japanese women as consumers}

Within their central role as housewife in the 1950s and 1960s, Japanese women established themselves as arbiters of the new urban household's image, taste, fashion and consumption. Department stores sold new appliances that aimed to 'rationalise housework' and 'project the housewife as a household expert and domestic manager' (Young 2003: 65). Through this role, women, especially housewives, came to be associated with a high level of consumer awareness and consumer behaviour, first as holders of the purse-strings within the Japanese household, and second as key players within community consumer groups. Japan's Shufuren (Housewives' Association) has played a leading role in the post-war consumer movement since its inception in 1948, demonstrating the importance of a gender perspective in bringing the Japanese government and producers to task over consumer concerns. Japanese women, particularly housewives, were increasingly viewed as knowledgeable and responsible consumers, aware of environmental issues, strong players in the development of consumer rights, and in themselves an active, identifiable consumer group in the domestic market. From the 1970s, there were two distinct consumer categories of Japanese women for advertisers and market researchers: working women (predominantly young, single women) and housewives (older, married women). Assmann (2003) describes how women's magazines in Japan have reinforced notions of gender roles and gender groups, emphasising the divide between working and home-making women. Implicit in her argument is that magazines are also the delineators of detailed 'rules' or 'instructions' on what certain groups of Japanese women should buy.

This categorisation of Japanese women into identifiable consumer groups has continued. A 1997 market report identified four key consumer types: (1) Silver (persons aged 50+); (2) Active Singles (unmarried working persons aged 20-39 years); (3) Youngsters (persons aged 10-24 years) and (4) Influencing Women (working women and housewives aged 20-49 years). This last category was made up of two sub groups, 'internalist housewives' and 'materialists', together comprising 21.4 per cent of the Japanese population. Internalist housewives were focused on their personal lifestyles, communities and the environment, and were the primary target group for a range of 'home-use products'. 'Materialist women' valued material goods and money as key drivers of happiness, and were 'clinging to the attitudes of the bubble period' through their propensity to buy luxury, fashion and branded goods (TrendScope 1997: 10, 16-17). A more recent consumer trend report by Yomiuri in 2008 identified 'ladies aged around 40' as one of the four key consumer profile categories in the Japanese market. These women had entered the working world during Japan's bubble economy, and were described as having 'lived in the lap of luxury... active, energetic women who continue to work after marriage...noted as a group with stable spending habits' (Yomiuri 2008). Whether homemaker or working, these women, mostly married and 30+ years of age, have been the obvious consumer target group for products such as household and kitchen appliances. 
This targeting was tied to the prevailing consensus that such women hold a substantial level of power in the Japanese household. They are responsible for the family budget, balancing income and expenditure, and favour stability and limiting debt, while projecting the image of an orderly, 'middle-class' home. A survey by JETRO in 1981 found that 43.0 per cent of married women took sole responsibility for the budget, and 40.7 per cent shared the responsibility with their husbands. Only 16.3 per cent of women responded that their husband ruled the family purse (JETRO 1981: 10). In the same survey, 59.1 per cent of women responded that they were solely responsible for the purchase of domestic appliances, while 37.2 per cent said they shared the purchase decision with their husband. Only 1.8 per cent responded that their husband was solely responsible for the purchase of a domestic appliance, compared to 32.7 per cent for an audio or TV purchase, and 44.2 per cent for a car.

The 1981 JETRO study also noted that consumer purchases were primarily of domestically produced products, but as purchasing power increased so would the desire to purchase imported goods. It also commented that 'the Japanese market is changing and it is not entirely coincidental that the Japanese woman - consumer and housewife - is also going through a process of evolution' (JETRO 1981: 1). While demand for foreign or international products, particularly in the areas of leisure, food and fashion, including luxury brands, did grow over the post-war decades, such products had to compete in price and quality within the forceful domestic market. When the Japan Market Research Bureau polled over 1,000 women in the Tokyo/Yokohama area in 1978, only 15 per cent agreed with the statement that 'most foreign products are of better quality than Japanese ones' (quoted in JETRO 1981: 18). Moreover, consumer products had to demonstrate that they were appropriate to, or could be absorbed into, the Japanese lifestyle. As Japanese homes and rooms were on average smaller than in the West, and were often multi-purpose, there was a need for flexibility, compactness and durability (JETRO 1981: 13), particularly apparent in relation to the consumption of home-ware, kitchen and electronic goods. Few Japanese housewives wanted to purchase a Western-style dinner service, for example, preferring to have an array of smaller plates and a variety of mix-and-match tableware products (JETRO 1981: 14). Japanese kitchens could not usually accommodate Western-size refrigerators or ovens, so domestically produced products dominated the market. Domestically produced electric rice cookers offered Japanese women the opportunity to cook rice in an efficient and compact appliance that took up little space in the kitchen, and was easily transported from one room to another for serving purposes.

The electric rice-cooker therefore developed as it did because of the importance of rice in Japanese daily meals, the centrality of rice-cooking to the (real or symbolic) role of the Japanese housewife, and as part of the technologically driven growth in Japanese manufacturing. As consumers, Japanese women, particularly married women, influenced what was produced through their need or desire to maintain their housewife role within the context of 'modern' life. The electric rice cooker offered the perfect adaptation of 'modern' technology to urban middle-class meal patterns and the lives that women were leading in their new urban housing. 


\section{The impact of the electric rice cooker}

In an attempt to add some consumer 'voices' to this chapter, I conducted a survey on the purchase and use of rice cookers. ${ }^{8}$ The primary target respondents were Japanese women who had purchased and used rice cookers. Although the survey is not comprehensive in terms of number of respondents, nor conclusively representative of the Japanese domestic market for this product, the responses can throw light on some of the issues explored in this chapter, particularly the key issue of gendered consumption of the electric rice cooker. The survey reinforced the suggestion that it is women who are the key consumers of rice cookers in Japan. Of all female survey respondents, 93 per cent had purchased a rice cooker for themselves, while 54 per cent had received a rice cooker bought for them. Of those who had received a rice cooker as a 'gift', 81 per cent said it had been purchased by another female, with the majority (55 per cent) receiving one from their mother (although 18 per cent of recipients said they had received one from their husband). When questioned as to whether they remembered, as children, their family purchasing an electric rice cooker, 54.3 per cent responded that they did, and of those, 83.5 per cent said that their mother had been the person who decided to purchase the rice cooker (compared to only 9.6 per cent who remembered their father as the purchaser of this appliance).

When questioned on their own purchasing decisions, a majority said they made their purchase choice based on technology ( 45.8 per cent ), compared to price (18.3 per cent ), size ( 7.5 per cent ), design ( 5.8 per cent ) and brand loyalty ( 1.7 per cent ). Only 34.7 per cent of all respondents said they were influenced by any form of advertising. A majority of respondents (72.5 per cent ) had purchased a rice cooker more than once; 11.1 per cent of this group had purchased one within the last 12 months, 45.3 per cent $1-5$ years previously, 29.1 per cent $5-10$ years previously and 14.5 per cent more than 10 years previously. Of those who had purchased more than one appliance, 45.3 per cent had purchased to replace a damaged model, and 25.6 per cent to upgrade to a newer-technology model. 49.3 per cent of respondents used their rice cooker at least once a day, 21 per cent on average 3-4 times per week.

When asked about the 'impact' of the electric rice cooker on the 'everyday lives of Japanese women' (including their mothers and grandmothers), 48.4 per cent responded that the appliance had had a 'very important impact', 35.2 per cent an 'important impact', and 13.1 per cent 'some impact'; only 3.3 per cent felt it had had 'little impact' or 'no impact'. When asked to comment freely on rice cookers more broadly, many respondents commented on the 'time-saving' nature of the appliance, stating how its simplicity, efficiency and reliability gave them more 'time', and that this time could be used more 'freely' and 'efficiently'. Many stated that the technology in modern rice cookers was crucial to this, particularly the 'automatic timer' function and the 'keep warm' function allowing for hot rice to be served at any time, enabling family members to eat separately if necessary. Many respondents also

\footnotetext{
${ }^{8}$ This was an online survey via www.surveygizmo.com that ran for three months from October 2010 to January 2011. A total of 135 completed responses were collected for analysis (117 responses were either abandoned by respondents or only partially completed and not suitable for analysis). All of the respondents were Japanese nationals (88 per cent living in Japan; the remaining 12 per cent currently living outside Japan). 97.4 per cent of respondents were female, with the majority married and aged in their 30s and 40s (breakdown by age: 4.3 per cent were $25-29$ years; 41 per cent in their 30s; 41 per cent in their 40s; 10.3 per cent in their 50s; and 3.5 per cent in their $60 \mathrm{~s}$; breakdown by marital status: 62.3 per cent were married; 25.4 per cent single, 7.0 per cent divorced, 2.6 per cent cohabiting and 2.6 per cent widowed).
} 
wrote that it 'reduced the burden' or 'shortened the time' required for housework or household chores.

While many women commented that it was relatively simple to cook rice using a donabe (earthenware pot) or pan over gas, most regularly used their rice cooker to cook plain, steamed rice. A few commented that the transition from gas cooking with a donabe saved some time and the need to be physically present, but was less than the transition from cooking rice with a traditional fire kamado. As one woman commented, 'it is impossible to imagine how difficult this was 70 years ago'. One respondent wrote 'my grandmother could not move away from the kamado, as she needed to often adjust the level of direct flame while she cooked the rice', and another commented: 'my mother's family used to cook rice for their large family using a kamado with firewood outside the house in the very early morning. It must have been hard work to prepare even two other side dishes. My grandmother was a teacher, and I cannot imagine how she combined work and being a housewife'. Several respondents commented that the electric rice cooker was a 'must have' or 'necessity' item.

Several respondents also made comments such as 'it is important that the rice is delicious because it is our staple food', and about rice being embedded in the 'culture' of the Japanese. One respondent felt the appliance had 'protected the Japanese food culture that is centred on rice', and another commented 'both my mother and I have a strong insistence on rice, and we have rice every day. I choose to buy delicious rice even if it costs more. We don't like to throw away left-over rice, so our main priorities are the ability to cook delicious rice and the "keep-warm" function of a rice cooker'.

It may be that the rice cooker has reached a mature point in its product lifecycle. One respondent commented that while 'there must be no family without a rice cooker in Japanese society, its impact is nowadays reduced. Microwaves are more influential'. Another said 'with the spread of musenmai [no-rinse rice], I find it sad that fewer and fewer people rinse rice and also cook rice without rice cookers'. Several respondents also commented on the continuing technology that keeps Japanese companies rolling out advanced models. One respondent wrote 'some expensive rice cookers are sold nowadays, but I think that the modest-priced rice cookers can still cook rice deliciously with their advanced technology', while another commented that 'recent rice cookers have too many functions. I think it's enough with minimum functions. The price is getting too high'. Other respondents wrote ' if I compare the rice cookers in my mother's generation (they were simple so there were not many parts to get worn out, and they lasted over 20 years), I think that rice cookers using rubber parts last only 7-8 years nowadays', and 'I see TV adverts with many high-tech rice cookers, but I don't understand the difference between IH [induction heating], maikon [microcomputer] and kamado-style cooking method appliances. I am happy when a rice cooker can cook rice; I have a simple one'.

Some responded more positively to the advancing technology: 'rice cookers are getting more convenient recently - you can rinse rice without scratching the inner bowl. They are also evolving, for example, there are products which avoid steam coming out upwards'. Another commented: 'I have tried a lot of rice cookers and I like the one I am currently using. There are quite big differences in the taste of rice 
cooked by different rice cookers. As long as the rice is delicious, any side dishes can be delicious, too!' One woman wrote 'I feel that the role of the rice cooker has moved from its initial role, which was to free women from housework, to that of enabling them to cook delicious rice. This shows in the fact that expensive rice cookers costing around $¥ 100,000$ sell well'. Another stated 'as a nation of rice eaters, rice cookers are absolutely indispensable for our lives. Now we have expensive models, with high-tech ability to cook the best rice (not too soft, not too hard, glossy as crystal, and moderately sticky). They can cost as much as $¥ 100,000$ or more. But we do not hesitate to purchase such a device, because we would like to enjoy great rice every day at home. The problem is that the models change too rapidly. We are sure the newest one is the best, so we try hard to resist its charm and not to purchase one after another. Actually, my mother (who is 74 years old) has a dozen rice cookers at home and evaluates which one is best. Ridiculous!'.

The comments of some respondents linked technology, history and the importance of rice, for example 'it seems that people move like a pendulum in time. Rice cookers have evolved from gas to electric ones, with modern timer and "keepwarm" functions. However, user feedback has suggested that rice cooked by gas or fire is better than that cooked by electric means (it might be a childhood memory of taste). In response to those users who are concerned about the old fire method of cooking, manufacturers have introduced pot and firepower functions into their electric rice cookers'. One woman commented that 'when my family first bought a rice cooker, it was a gas rice cooker. But my family was getting large, and I think that the electric rice cooker became necessary for my mother to cope with the preparation of lunch boxes and different meal times every day. The performance of modern rice cookers bears no comparison to the old ones. Previously, the rice became yellowish in colour and got hard when you left it in a "keep-warm" function, but nowadays the rice remains soft and delicious, and there are functions other than for cooking rice. At the same time, however, frozen foods and microwave technology mean we can have delicious rice without sticking to freshly cooked rice. I think that the functions sought after by those in the 1970s and 1980s are quite different from the demands of the current generation. I think that [the rice cooker] was a great influence for women's housework life and time in the 1970s and 1980s, but now I feel it is different'.

Overall there is a sense from the survey respondents that the electric rice cooker played a key role in the ability of women to go out to work and still easily produce an evening meal based around rice. One women in her 50s said 'for my generation, rice cookers with a timer setting ......... were available, so we set the timer in the morning and we could go to work'. Another commented 'the number of working women is increasing. When we have to prepare breakfast in the early morning and dinner after work, using an electric rice cooker means the rice is ready to eat. I think this makes women feel more free. I feel it gives them the ability to not only cook rice, but breathe, and face other things while it's cooking.' Other respondents wrote 'as rice cooking has become easier, I think women can work more easily', and 'I think that rice cookers greatly contributed to women's freedom to work in our society, especially since the timer setting became available'. 


\section{Concluding Comments}

In focussing on the history of the automated electric rice cooker since its development, inception and launch on to the Japanese domestic market in the 1950s, this chapter has tried to integrate the manufacturing side of the story, with specific reference to Toshiba, and the consumer side of the story, in particular the role of women as consumers. After 55 years the cooker remains important. A Toshiba manager commented to me that the electric rice cooker remains a core product within the company's kitchen and household appliance division, and that 'the importance of the product is high, as it is the product that boils the staple food for the Japanese people'.

This 'modest' appliance in many ways helped to 'revolutionise' the life of the average Japanese woman. Sadly, Fumiko, the original female consumer of this product, does not appear in the Project $X$ documentary programme. She died, aged only 45, in 1959, just as the rice-cooker boom was hitting Japan, but not before reportedly receiving in hospital letters from housewives all over Japan, recording how thankful they were to be released from the hard work of daily rice cooking and how they now enjoyed more relaxing mornings and evenings. I like to think she would be pleased that this impact has continued. As one of my survey respondents commented: 'it was a good experience to think about the rice cooker as I have never really thought about this. I am 34 years old, so electric rice cookers have existed since I was born. I hadn't thought about its impact on women and how it helps to reduce time and effort'.

\section{References}

Assmann, Stephanie (2003). 'Japanese Women's Magazines: inspiration and commodity' in Electronic Journal of Contemporary Japanese Studies. Discussion Paper 6, 2003.

Bowden, Sue and Avner Offer (1994). 'Household appliances and the use of time: the United States and Britain since the 1920s' in Economic History Review, SLVii, 4.(1994)5 PP- 725-748.

Costa, J. ed., (1994). Gender Issues and Consumer Behaviour. Sage Publications.

de Grazia, Victoria, ed.(1996). The Sex of Things: Gender and Consumption in Historical Perspective. Berkeley: University of California Press.

de Vries, Jan (2008). The Industrious Revolution. Cambridge: Cambridge University Press.

Francks, Penelope (2009). The Japanese Consumer: An Alternative Economic History of Modern Japan. Cambridge: Cambridge University Press

Francks, Penelope (2009). 'Inconspicuous Consumption: Sake, Beer, and the Birth of the Consumer in Japan' in The Journal of Asian Studies, Vol.68, No.1, February 2009, pp.135-64.

\footnotetext{
${ }^{9}$ Email communication with Manager, Corporate Government \& External Relations Division, Toshiba, Tokyo, January 2011.
} 
Goo (2005). (Online Blog) Kyō no koto arekore to...: Toshiba ga denkigama o hatsubai shita hi (This and That on this Day...: the day Toshiba launched the electric rice cooker). 10th December 2005. Accessed at:

http://blog.goo.ne.jp/yousan02/e/b30cf4698e2c3b76afa1f1ebb6dd2057?st=1

JETRO (1981). The Female Factor in Japan's Import Market: a survey of the purchasing attitudes and experience of 687 women. Japan External Trade Organization (JETRO), Tokyo.

Kosuge, Keiko (1991). Nippon Daidokoro Bunkashi (Cultural History of the Japanese Kitchen). Tokyo: Yūzankaku Shuppan

Ministry of Economy, Trade and Industry (METI). Accessed at:

http://www.stat.go.jp/english/data/chouki/08.htm

Macnaughtan, Helen (2005). Women, Work and the Japanese Economic Miracle: the case of the cotton textile industry, 1945-75. RoutledgeCurzon.

Macnaughtan, Helen (2006). 'From 'post-war' to 'post-bubble': contemporary issues for Japanese working women' in P. Matanle \& W. Lunsing eds., Work, Employment, and Society in Contemporary Japan. Palgrave Macmillan.

Nakano, Yoshiko (2009). Where There Are Asians, There are Rice Cookers: How "National" Went Global via Hong Kong. Hong Kong University Press.

NHK (2002). Project X: Challengers. Documentary No.42.

Panasonic Corporation (2011). Panasonic Corporate History: innovative products, 1956, automatic rice cooker. Accessed at:

http://panasonic.net/history/corporate/products/inp1956.html

Partner, Simon (1999). Assembled in Japan: Electrical Goods and the Making of the Japanese Consumer. Berkeley: University of California Press.

Partner, Simon (2001). 'Taming the Wilderness: The Lifestyle Improvement Movement in Rural Japan' in Monumenta Nipponica, Vol. 56, No. 4 (Winter, 2001), pp. $487-520$

Sand, Jordan (2003). House and Home in Modern Japan: architecture, domestic space and bourgeois culture 1880-1930. Harvard University Asia Center.

Tamaki, Etsuko (2003). Sazaesan ni miru sengo Nihon no kurashi (The lives of postwar Japanese, as seen through 'Sazae-san'). Jissen Women's University, Faculty of Human Life Sciences.

Toshiba Corporation (2009). Toshiba Project Technology History. Accessed at: http://museum.toshiba.co.jp/history/1 goki/1955rice.html

Toshiba Corporation. Firsts of Their Kind. (Toshiba documentation). 
TrendScope (1997). Trend Watch: The New Consumer Trends in Japan.

TrendScope, August 1997, Tokyo.

Yamaguchi, Masatomo (1988). Daidokoro kūkangaku: sono genkei to mirai (A study of kitchen space: the prototype and the future). Tokyo: Kenchiku Chishiki.

Yamaguchi, Masatomo (2008). 'The Japanese Kitchen: modern era to innovation'. Accessed at: http://1st-japanese-food.blogspot.com/search?q=yamaguchi

Yomiuri (2008). About Japan: Consumer Trends. Accessed at:

http://adv.yomiuri.co.jp/m-data/english/market/about_japan2.html

Young, Louise (1999). 'Marketing the Modern: Department Stores, Consumer

Culture, and the New Middle Class in Interwar Japan', in International Labor and Working-Class History. No. 55, Spring 1999, pp. 52-70. 